Administrative Issues Journal: Connecting Education, Practice, and Research, Winter 2019

Vol. 9, No. 2: 1-11. DOI: 10.5929/9.2.3

\title{
Attaining philosophical alignment: Localizing systemic change through adaptive professional development
}

\author{
Laura B. Kent, Ph.D. \\ University of Arkansas
}

\begin{abstract}
This article describes the impact of an adaptive professional development program for $\mathrm{K}-8$ mathematics teachers to enhance their implementation of standards that were streamlined to promote improved student learning and achievement. Students from the participating district scored higher than the state average and a neighboring district during the three years of implementation. Survey data showed growth in teacher enactment of dynamic problem-posing lessons during the three years of professional development. Peer classroom observations and shared reviews of student work samples were considered pivotal to teachers changing their instructional practices.
\end{abstract}

Keywords: Mathematics Teaching, Adaptive Professional Development, Formative Assessment, Coaching

"Progress is impossible without change, and those who cannot change their mind cannot change anything" (George Bernard Shaw)

\footnotetext{
$\mathrm{C}$ hange is perhaps one of the most discussed topics in education. George Bernard Shaw captured the rationale succinctly and accurately. Yet, changes in education tend to be greeted with apprehension by all levels of stakeholders, from top-level administrators to individual students in the classroom. While few would argue with Shaw's assertion, the question remains why changes in instructional patterns remain elusive for many teachers. In the area of mathematics teaching and learning, experts have advocated for changes for decades (NCTM, 1989, 2000, 2014; National Research Council, 1989). From a global perspective, advances in curriculum and technology, as well as the flourishing knowledge of individual and social cognition, have initiated a variety of opportunities for change across a wide spectrum of instruction and learning in mathematics.

One of the recent attempts at change in mathematics education was the release of the Common Core State standards for mathematics. These standards were an attempt to consolidate previous standards documents that were perceived by educators to be disjointed and superficial in terms of content coverage (McCallum, 2015). Early on, there was resistance to implementing Common Core and since the release of the document in 2010, most states have modified and adopted state standards to varying degrees of similarity to the Common Core Standards (Jochim, \& McGuinn, 2016).
}

\section{Systemic Change}

Descriptions of teacher change within the context of professional development are multifaceted and complex (Goldsmith, Doerr, \& Lewis, 2014; Guskey, 2002; Clarke \& Hollingsworth, 2002). Goldsmith, Doerr, \& Lewis (2014) summarized the research on teacher learning and organized the studies in terms 
of Clarke and Hollingsworth's (2002) four interconnected domains: personal, practice, external, and outcomes (p. 8). Sustained professional development attends to all three domains and requires support from all stakeholders including teachers, students, parents, and administrators. The majority of the studies of teacher learning focused on identity, beliefs, dispositions and instructional practice, with fewer studies focused on the role of student thinking and instructional tasks (p. 11).

This article examines the impact of professional development programs that focused on dynamic problem-posing (DPP) across a broad range of grade levels (K-8) in one school district over a five-year period. The aim of DPP was to use a structured framework of problem-posing to improve assessment of student ideas and approaches to solve problems for future instructional decision-making. Smithsville School District is in the southeastern part of the US. The descriptions of the professional development programs' common themes highlight the advantages of a philosophically aligned approach to mathematics teaching and learning. The advantages included increased teacher collaboration and improved student achievement.

\section{External Factors}

Any type of major systemic change within a district or a school requires administrative support for a host of practical and logistical reasons. Making provisions for teachers' time and financial allocation for resources are among the most important reasons for institutional support for professional development that might lead to changes in instructional practice. Support from administrators usually requires evidence that professional development has a proven track record of success, both in terms of teachers and students. In terms of students, improvement in student learning and achievement are baseline indicators that would influence the level of support provided for a new initiative or PD program.

Smithsville school district was one of many districts in a state which had embarked on an effort to improve mathematics teaching and learning in the early elementary grades. Professional programs that focused on increasing teachers' pedagogical content knowledge in the areas of whole numbers, fractions, and algebraic reasoning were considered foundational concepts to success in more advanced mathematics courses (National Mathematics Advisory Panel, 2008). Additionally, the Common Core Standards reflected these recommendations as well. For instance, the Common Core Standards were written such that K-5 algebra standards were integrated with the number and operations standards to reflect the growing knowledge base of students' computation strategies that reflected a variety of generalized properties of arithmetic, such as the distributive property.

\section{Changing Practice}

Professional development programs designed to initiate changes in instructional practice emphasize the significance of successful implementation of new ideas in potentially changing teachers' beliefs and attitudes (Guskey, 2002; Clarke \& Hollingsworth, 2002). Successful implementation can be defined by a variety of factors including student learning, student achievement, motivation, and other aspects of efficacy. In the case of mathematics instruction, professional development programs must address conflicting views about how teachers, individually and collectively, learned mathematics compared to practices that would serve a wider scope of diverse learners.

Guskey (2002) suggested, "Teachers who have been consistently unsuccessful in helping students from educationally disadvantaged backgrounds to attain a high standard of learning, for example, are likely to believe these students are incapable of academic excellence. If, however, those teachers try a new instructional strategy and succeed in helping such students learn, their beliefs are likely to change" ( $p$.

KENT / DOI: 10.5929/9.2.3 
384). Teachers' lack of success in helping their own students learn mathematics may stem from a mismatch between their perceptions of their own success learning traditional methods and algorithms and their students' inabilities to learn these same methods in the same manner in which they once learned.

Experimentation is considered a key component of school context factors that provide potential openings to changes in practice (Clarke \& Hollingsworth, 2002). For many teachers, the experimentation component may be the most difficult step. Their perception of their own students' lack of ability in mathematics may inhibit their willingness to attempt a new method, fearing that it will fail and reflect on them negatively. They also may be concerned that if their students do not show success early on with the new strategy that the students themselves will become less engaged and regress academically.

The importance of the experimentation component has led to important changes in the emphasis on professional development programs. The movement away from seminar-only sessions that tend to focus more on hypothetical classroom scenarios to lesson study or classroom-embedded sessions have provided more opportunities for teachers to learn how change is possible in real classrooms with real students in real-time (Nielsen, Steinhorsdottir, \& Kent, 2016; Loucks-Horsley, Love, Stiles, Mundrey, \& Hewson, 2003). Allowing teachers to co-plan, and even in some cases co-teach lessons with students, can provide the impetus for them to try new methods in ways that seminar sessions fail to provide.

\section{One Problem in a Lesson?}

The idea of increased emphasis on problem-posing and problem solving emerged as a viable approach to mathematics teaching as a result of international comparisons of student achievement in the United States and other countries such as Japan. For example, the eighth-grade video study from the Third International Mathematics and Science Study showed that students in US classrooms spent more time repeating procedures and less time on application problems than students in Japanese classrooms (Hiebert, et al., 2005). Other inferences drawn from these types of studies included the comparison that the mathematics curriculum in the United States was "a mile wide and an inch deep," and that content coverage was lacking in conceptual depth in comparison to higher-performing countries. As a result of these studies, discussions were initiated on how to address lackluster student performance in mathematics in middle school and beyond. National panels were formed and mathematicians were recruited to reformulate national mathematics standards that had been in place for several decades (NCTM 1989). The Common Core Standards for Mathematics (CCSM) was created to consolidate and minimize standards to guide teachers toward more in-depth instructional strategies (National Governors Association, 2010).

These national changes prompted many districts to investigate and invest in professional development programs to help teachers implement the new standards for mathematics and English. Programs that incorporated research, ideas and instructional methods for in-depth exploration of content were prioritized during the initial rollout of the Common Core Standards. The CCSM elementary grades standards consolidated number and algebra content and described them as "operations and algebraic thinking.": This type of integration was informed, in part, by the recognition that generalized number computation strategies reflect foundational properties such as the distributive property of multiplication over addition emphasized in later algebra courses (Carpenter, Franke, \& Levi, 2003).

The goals for professional development programs were designed to enable teachers to implement these new standards. Districts moved away from historical textbook adoption cycles and toward standardsbased approaches that emphasized localized curriculum construction and adaptation. Writing and posing

KENT / DOI: 10.5929/9.2.3 
mathematics problems to students was known to be challenging for teachers (Singer \& Voica, 2013). Smithsville was one of many districts that also hired specialized instructional coaches to facilitate the implementation of CCSM. Many of these instructional coaches experienced their own success in implementing standards-based approaches as evidenced by increased student test scores and other measures of mathematics learning.

\section{Philosophical Alignment with DPP}

Smithsville School District is a mid-size school district in the south-central part of the United States with roughly 4000 students. In terms of student enrollment, Smithsville is roughly three times the size of the surrounding rural school districts but, also, about one-third of the size of surrounding suburban districts. During the six years of engagement in this ongoing mathematics professional development initiative, the district was approximately $55 \%$ in terms of students on free and reduced lunch and $53 \%$ of the students were considered to be living below the poverty level. The district is culturally diverse with $55 \%$ Caucasian, 30\% Hispanic/Latino and 15\% Native American, African American, Asian, and other.

The district leadership for mathematics instruction included the three instructional facilitators for mathematics and the district curriculum leader. The three mathematics coaches across grades K-8 in conjunction with the district curriculum leader decided on an adaptive model of mathematics professional development that could work across all grade levels and emphasized problem-solving (Koellner, \& Jacobs, 2015). The professional development sessions were subdivided into three grade bands: K-2, 3-5, and 6-8. All teachers responsible for mathematics instruction were participants in sessions specifically tailored to their grade band. Teachers attended three-year professional development programs either from specialists who worked with Smithsville only (K-2 and 3-5) or regional workshops with nearby districts (6-8). The philosophy of the professional development (PD) programs was similar across all three bands: problem-posing, formative assessment, teaching methods that connect students' strategies for solving problems to district and state standards and promoting productive discourse during mathematics lessons. Differences in focus for the PD sessions focused primarily on the different content standards for different grade levels and different types of schedules.

The format for the PD sessions (all held during the school year) followed a spiral sequence:

- Year 1 - Posing problems, strategy development, number concepts

- Year 2 -Teacher questioning, classroom discourse, integration of content

- Year 3-Integration of instructional strategies

Each year was comprised of three seminar-style sessions and four classroom embedded sessions. Teachers were nominated by instructional facilitators to serve as host teachers for the classroom embedded sessions. Problem-posing lessons typically involve the posing of a contextualized situation in which students are not given methods or strategies, in advance, from the teacher. Students are given time to explore the problem and decide on their own strategies for solving the problem. During this time, the teacher observes and assesses them individually to determine mathematical correctness of strategies and differences in approaches to solving the problem. Some teachers use this time to identify strategies that could be shared by individual students to help facilitate a learning goal for the lesson or the problem posed. The culmination of the lesson is the sharing of three to five different strategies and questioning by the teacher and/or other students to highlight mathematical ideas and connections among the different strategies.

KENT / DOI: 10.5929/9.2.3 
Initially, teachers were overwhelmed by the idea of an entire math lesson devoted to a single problem. This idea contradicts the traditional routine of mathematics lessons in the US in which the beginning of the lesson is devoted to reviewing the previous day's material, followed by the introduction of new content which includes showing methods of solutions, followed by students practicing the procedures just shown to them.

Most teachers entered the professional development unsure that their students were capable of solving mathematics problems unless first shown the methods to use to resolve them. Teachers struggled to avoid the dilemma of "telling" students how to do mathematics as other research has found (Baxter \& Williams, 2010). Even though there are videos of students solving problems without advanced instruction, teachers initially commented, "my students would never be able to do that." The inclusion of sessions that involved participating teachers in watching their peer teachers implement problem-posing lessons became a significant component of the professional development program across the district (Nielsen, Steinhorsdottir, \& Kent, 2016). Many teachers in their reflections commented that the peer classroom sessions were the most significant in their own successful implementation of the ideas presented in the professional development program.

\section{Dynamic Problem Posing (DPP)}

Dynamic Problem Posing or DPP was the predominant model of mathematics instruction across grades K8. DPP focused on three central components: writing problems that were personalized to individual teacher's students, posing those problems using strategies that were engaging to students such as the use of real-life stories to motivate problem-solving, and careful selection and sequencing of the sharing of strategies.

The DPP-PD model also included a component that gave specific attention to facilitating Number Talks (Parrish, 2010) in addition to problem-posing. According to Mrs. Bennett (mathematics coach for grades K-2), "Including Number Talks as part of our PD provided a structure for our teachers to use to practice wait time, help our students verbalize their thinking and make algebraic connections." A typical Number Talks lesson might include posing a true-false equation or open number sentence. Mrs. Bennett and other mathematics coaches in the district supported their teachers to include Number Talks mini-lessons that were separate from the problem-posing lessons.

Another adaptive aspect of DPP was to facilitate the "Launch, Think, Solve, \& Share" structure to the problem-posing lessons. Teachers were given time during the PD sessions to write problems tailored to the interests and diverse ability levels of their students. They were also encouraged to develop and use anecdotal recordkeeping systems to organize individual student's strategy progressions. They were given time during the seminar sessions to reflect and make instructional decisions based on these records and observe other teachers within the district apply ideas from the PD.

The localized approach to the mathematics DPP-PD allowed for opportunities for teachers to make personalized connections by observing their students engaging with the ideas presented. It also provided direct opportunities for communication between the teachers and the mathematics coaches. Both the teachers and coaches provided input on the direction of the PD prior to, and following, the sessions. For example, gaps in vertical alignment across grade levels became apparent in the second year of the PD program. The PD facilitator made adjustments to the PD to allow for planning across grade levels to assure that the necessary content standards were adequately addressed in future years.

\section{Student Outcomes}

KENT / DOI: 10.5929/9.2.3 
Smithsville showed consistent scores above their state average for grades 1-4 on standardized measures of student achievement and neighboring districts like Garner. Figure 1 shows comparisons for grades 12. In years 1-4, Smithsville students on average, scored $19 \%$ higher than the state average. In year 5 , the scores plateaued and were only $11 \%$ higher than the state average.

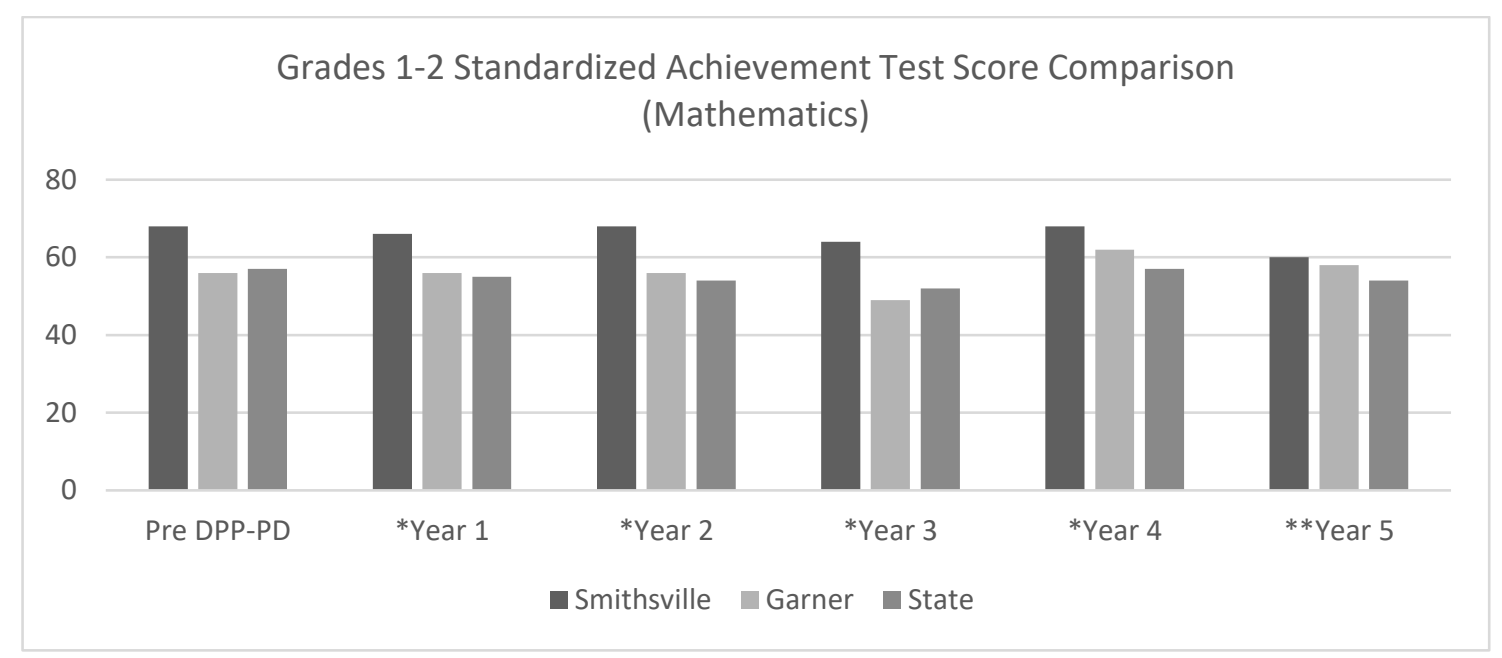

Figure 1. ITBS National Percentile Rank Comparisons for Grades 1-2. *Years participating in adaptive PD. **Participation ended.

Figure 2 shows comparisons for grades 3-4. A similar pattern showed a higher percentage achievement difference between Smithsville and a neighboring district, and they were on average $20 \%$ higher than the state in participating years. One notable difference is that the scores for Smithsville remained higher than the state average a year after PD officially ended. Year 3 data was not included as a test based on CCSS was used for that year only.

\section{Grades 3-4 Standardized Achievement Test Score Comparison \\ (Mathematics)}

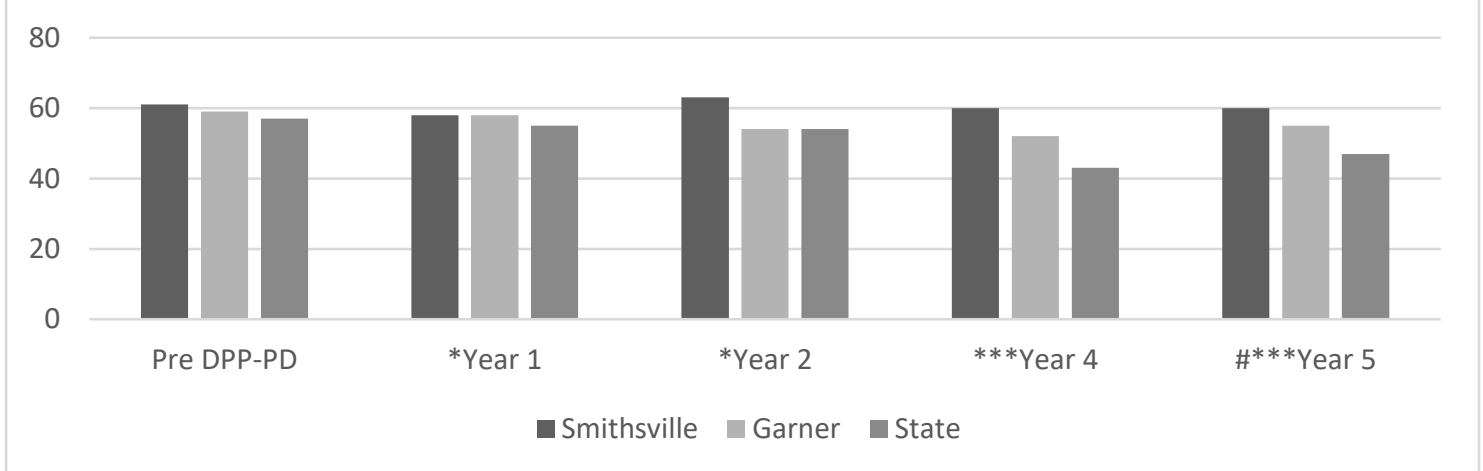

Figure 2. Grades 3-4 Test Score Comparisons. *ITBS National Percentile Rank. **Year 3 not included due to a test that was used one year only. ***Year 4-5 ACT Aspire scores based on percent of students classified as "proficient or advanced". \#***Participation ended

The middle grades comparison in mathematics showed that the mathematics DPP-PD had less impact in comparison to the neighboring district and the state in terms of achievement as shown in Figure 3. Several factors potentially contributed to this leveling out in the middle grades. One factor was that

KENT / DOI: 10.5929/9.2.3 
mathematics teachers in grades 6-8 from Smithsville were participating in professional development that was not as adaptive to their district as the lower grade bands. While based on similar principles, it was offered to teachers regionally and therefore there was less emphasis given to the needs of these teachers and more based on a scripted PD to reach the general audience of teachers. Another possible contributing factor was that both the grades 1-2 mathematics coach and the grades 3-4 mathematics coach had double the years of experience with the PD model (six years) compared with the middle grades mathematics coach (three years).

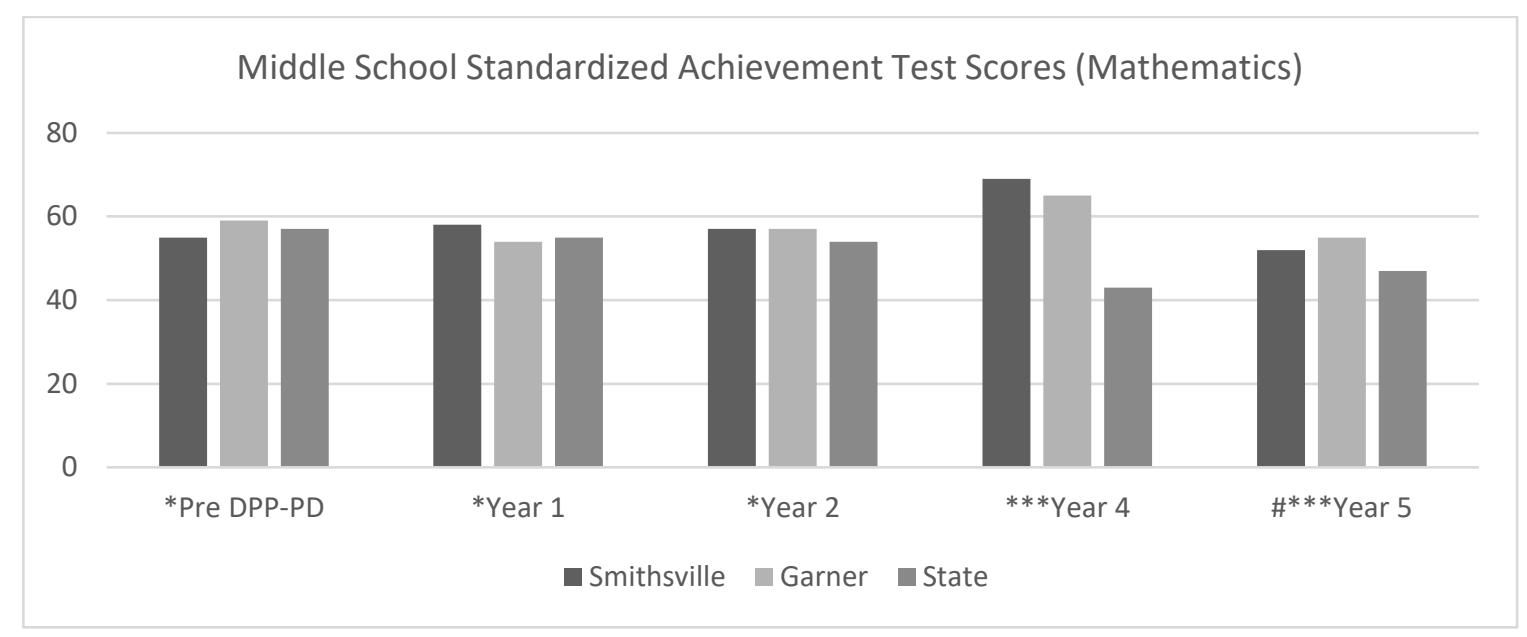

Figure 3. Middle Grades Test Score Comparison. *ITBS National Percentile Rank. **Year 3 not included due to a test that was used one year only. \#***Year 54-5 ACT Aspire scores based on percent of students classified as "proficient or advanced"

\section{Enacting DPP Lessons}

Teachers in Smithsville School District showed differing levels of implementation of DPP lessons. Two cohorts of teachers participated in three years of PD designed around DPP. The three mathematics coaches identified groups of teachers based on knowledge of the standards and their perception of teachers who would be most receptive to the DPP approach. The DPP-PD was facilitated by the expert teachers and mathematics leaders in the region. The $\mathrm{K}-2$ and $3-5$ sessions were all conducted onsite during the academic year. The grades 6-8 sessions were mostly conducted onsite, with the exception of three days each year held during the summer months.

Each PD session focused on supporting the enactment of DPP lessons. Facilitators shared problems based on research and number sets that maximized students' opportunities to problem solve using a variety of strategies. For example, division problems in which the number of groups was unknown was a focus of discussion across all grade levels as a type of problem accessible to students that elicited a variety of additive and multiplicative strategies (Kent, Empson, \& Nielsen, 2015). Rather than hypothesize possibilities of what might happen if this type of problem was posed, the facilitator would work with the district mathematics coaches to pose the problem in an actual classroom to see what happens with students in "real-time" circumstances. Teachers would have the opportunity to watch their peer teachers pose the problem and attend to the launch of the problem, student perseverance in solving the problem, and methods teachers used to orchestrate student sharing of their strategies. The student work was collected on these occasions and the teachers would have the opportunity to more closely examine the student work and receive feedback from the teacher who hosted the actual lesson.

KENT / DOI: 10.5929/9.2.3 
There were three identified levels of enactment of DPP lessons: every day, sometimes, rarely. These data were collected through survey self-reports completed on the last day of PD each spring of participation. Table 1 shows the frequency in which DPP lessons were enacted (grades K-8) throughout the three years of the DPP-PD. Cohort A teachers across the K-8 grades were selected for the first offering of DPP-PD because of previously demonstrated strengths in the classroom as perceived by their respective mathematics coaches. More of them already showed a propensity for following the recommendations of the Common Core Standards at the time. The DPP-PD served the purpose of deepening teacher knowledge of students and content (Hill, Ball, \& Schilling, 2008). Not all teachers in either cohort A or cohort B were able to fully implement DPP daily after three years of ongoing PD. However, the majority of teachers reported that they used DPP sometimes or every day as the majority of their instructional approach by the end of the three-year PD program.

Table 1

Teachers' reported frequency of DPP lessons

\begin{tabular}{|c|c|c|c|c|c|c|}
\hline \multirow[t]{2}{*}{ Year } & \multicolumn{3}{|c|}{ Cohort A $(n=62)$} & \multicolumn{3}{|c|}{ Cohort B $(n=55)$} \\
\hline & Every day & Sometimes & Rarely & Every day & Sometimes & Rarely \\
\hline 1 & 8 & 33 & 21 & & & \\
\hline 2 & 12 & 39 & 11 & 4 & 20 & 21 \\
\hline 3 & 21 & 34 & 7 & 13 & 26 & 16 \\
\hline 4 & & & & 18 & 23 & 14 \\
\hline
\end{tabular}

\section{Teacher Support}

All three of the mathematics coaches for Smithsville attended all DPP-PD sessions with both cohort A and cohort $B$ teachers for their respective grade bands. They also supported individuals and groups of teachers by conducting demonstration lessons and facilitating professional learning communities. The launch of the lessons was sometimes challenging for teachers. Therefore, the mathematics coaches would assist teachers in writing problems that relate to students' lives (i.e., using student names from the class, using their interests in developing story contexts, etc.). They would also model ideas for helping students visualize the story situations using objects or drawings.

Another challenge for teachers implementing DPP lessons was in relation to the pacing of lessons and allowing for productive struggle. Some teachers would step in early to help students without giving them time to think about problem situations and would correct their errors without first determining what the student was thinking. The mathematics coaches would focus on the Standards for Mathematical Practice in the Common Core Standards (National Governors Association, 2010). In particular, the first standard that encourages students to "make sense of problems and persevere in solving them."- Teachers were given suggestions on how to differentiate lessons and how to encourage students to try different strategies if they solved the problem quicker than their peers. Mathematics coaches provided instruments and suggestions to help teachers keep track of students' strategy progressions.

The DPP-PD sessions focused on different methods for orchestrating students' sharing of their strategies based on best practices (Smith \& Stein, 2011). However, many of the teachers wanted additional guidance from the mathematics coaches on using student work to highlight specific mathematics goals and standards. Suggestions such as choosing strategies that may help students overcome a misconception or make sense of mathematical notations were explored during times when mathematics coaches were observing lessons. Teachers were encouraged to give follow-up problems to further assess student learning of the intended goal.

KENT / DOI: 10.5929/9.2.3 
District support included providing release days during the school year and meeting rooms at the different buildings to host PD sessions. Substitute teachers were paid for by the district. The PD facilitators were also paid by the district to conduct the sessions both onsite and, in the case of the grades 6-8 PD, at regional locations. The building level principals provided additional supports in the form of additional release time for the professional learning community meetings to analyze student work and plan future lessons.

\section{Sustainability Challenges}

The challenges of sustaining an adaptive PD model like DPP have been numerous according to all three mathematics coaches. Mrs. Bennett reiterated the results shown in Figures 1-3, that there were substantial increases in student achievement in years one, two, and four of DPP implementation, but then a leveling off after the PD sessions ended. Other challenges included unavoidable issues related to teacher retirement and teacher relocation to other districts. Coinciding with these changes were shifts in administrative positions within the district. The curriculum leader retired and new principals were hired. Although efforts were made to maintain DPP as a district specialized model of instruction for grades K-8, there were pressures from high school mathematics teachers within the district to revert to more traditional methods.

There were also pressures from new administrators to incorporate a more specialized model advocated at the state level. According to Mrs. Bennett, these pressures complicated enactment of DPP because both the mathematics coaches and the teachers felt that they were being expected to participate in specialized PD programs that were in some ways redundant of what they had already experienced, which they perceived as devaluing their already gained expertise with DPP.

\section{Change and Progress}

According to Hargreaves and Fink (2003), "The promise of sustainable success in education lies in creating cultures of distributed leadership throughout the school community, not in training and developing a tiny leadership elite" (p. 700). Smithsville continues to adjust to ongoing changes in leadership, curriculum, and standards both within the district, regionally, and statewide. The mathematics coaches continue to work with teachers at all levels of expertise and develop new teacher leaders to guide new teachers in the district. As new, problem-based curriculum materials become available for use, professional learning communities continue to be utilized to discuss best ideas for DPP lessons.

As Bernard Shaw noted, progress is dependent on change. Continually changing to show progress can be confounding to teachers. Leaders at all levels grapple with the challenge of demonstrating that student learning in mathematics is improving even as standardized test scores plateau for some grade levels. Even as Smithsville reported that their first group of sixth graders to receive six years of DPP based instructional strategies scored the highest of any sixth-grade class on several of the newest standardized test score results, some of the lower grades scores stayed stagnant during the same time period. The inclusion of adaptive PD programs such as DPP shows promise of changing teachers' practice and improving student learning across a wide band of grade levels across many years. The key factor for Smithsville was the ongoing work of philosophical alignment among teachers and facilitators across the district during and beyond the specific professional development program.

\section{References}

Baxter, J. A., \& Williams, S. (2010). Social and analytic scaffolding in middle school mathematics: Managing the dilemma of telling. Journal of Mathematics Teacher Education, 13(1), 7-26.

KENT / DOI: 10.5929/9.2.3 
Campbell, P. F., \& Malkus, N. N. (2011). The impact of elementary mathematics coaches on student achievement. The Elementary School Journal, 111(3), 430-454.

Carpenter, T. P., Franke, M. L., \& Levi, L. (2003). Thinking mathematically. Portsmouth, NH: Heinemann.

Clarke, D., \& Hollingsworth, H. (2002). Elaborating a model of teacher professional growth. Teaching and teacher education, 18(8), 947-967.

Goldsmith, L. T., Doerr, H. M., \& Lewis, C. C. (2014). Mathematics teachers' learning: A conceptual framework and synthesis of research. Journal of mathematics teacher education, 17(1), 5-36.

Guskey, T. R. (2002). Professional development and teacher change. Teachers and teaching, 8(3), 381391.

Hargreaves, A., \& Fink, D. (2003). Sustaining Leadership. The Phi Delta Kappan, 84(9), 693-700.

Hiebert, J., Stigler, J. W., Jacobs, J. K., Givvin, K. B., Garnier, H., Smith, M., ... \& Gallimore, R. (2005). Mathematics teaching in the United States today (and tomorrow): Results from the TIMSS 1999 video study. Educational Evaluation and Policy Analysis, 27(2), 111-132.

Hill, H. C., Ball, D. L., \& Schilling, S. G. (2008). Unpacking pedagogical content knowledge: Conceptualizing and measuring teachers' topic-specific knowledge of students. Journal for research in mathematics education, 372-400.

Jochim, A., \& McGuinn, P. (2016). The politics of the Common Core assessments: Why states are quitting the PARCC and Smarter Balanced testing consortia. Education Next, 16(4), 44-53.

Kent, L. B., Empson, S. B., \& Nielsen, L. (2015). The richness of children's fraction strategies. Teaching Children Mathematics. National Council of Teachers of Mathematics. 22(2), 84-90.

Koellner, K., \& Jacobs, J. (2015). Distinguishing models of professional development: The case of an adaptive model's impact on teachers' knowledge, instruction, and student achievement. Journal of Teacher Education, 66(1), 51-67.

Loucks-Horsley, S., Love, N., Stiles, K. E., Mundry, S., \& Hewson, P. W. (2003). Designing professional development for teachers of science and mathematics. Thousand Oaks, CA: Corwin Press.

McCallum, W. (2015). The common core state standards in mathematics. In Selected regular lectures from the 12th international congress on mathematical education (pp. 547-560). Springer, Cham.

National Council of Teachers of Mathematics. (1989). Curriculum and evaluation standards for school mathematics. Reston, VA: NCTM.

National Council of Teachers of Mathematics (NCTM). (2000). Principles and standards for school mathematics. Reston, VA: Author.

National Council of Teachers of Mathematics (NCTM). (2014). Principles to actions: Ensuring mathematical success for all. Reston, VA: Author.

National Governors Association Center for Best Practices, Council of Chief State School Officers. (2010). Common Core State Standards for mathematics. Washington, DC: Author.

National Mathematics Advisory Panel. (2008). Foundations for success: The final report of the National Mathematics Advisory Panel. US Department of Education.

KENT / DOI: 10.5929/9.2.3 
National Research Council. (1989). Everybody counts: A report to the nation on the future of mathematics education. National Academies Press.

Nielsen, L., Steinhorsdottir, O., \& Kent, L B. (2016). Responding to student thinking: Enhancing mathematics instruction through classroom based professional development. Middle School Journal, 47(3), 17-24.

Singer, F. M., \& Voica, C. (2013). A problem-solving conceptual framework and its implications in designing problem-posing tasks. Educational Studies in Mathematics, 83(1), 9-26.

Smith, M. S., \& Stein, M. K. (2011). Five practices for orchestrating productive mathematics discussions. Reston, VA: National Council of Teachers of Mathematics.

\section{About the Author}

Laura B. Kent (Ikent@uark.edu) is an associate professor of mathematics education at the University of Arkansas. She is interested in students' mathematical thinking and enhancing pedagogical content knowledge through classroom embedded professional development. 